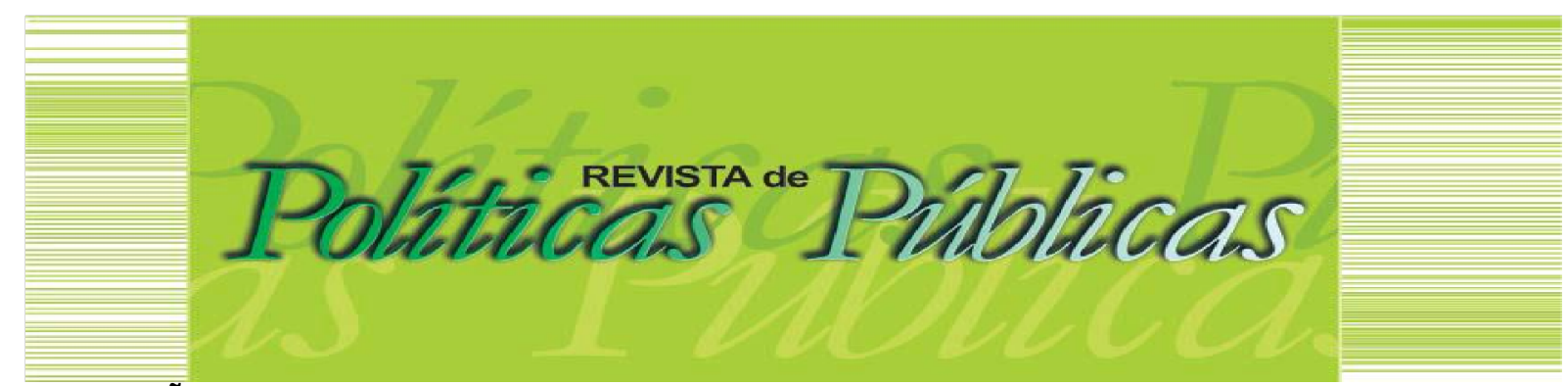

\title{
RELAÇÕES QUE PROMOVEM E REPRODUZEM A DESIGUALDADE E O RACISMO NO BRASIL
}

\author{
Antônio Eugênio Furtado Corrêa 1 \\ Eugénia da Luz Silva Foster² \\ Elivaldo Serrão Custódio 3
}

\section{Resumo}

$\mathrm{O}$ artigo tem por objetivo refletir sobre relações que, ao longo da história do Brasil, promovem, estruturam e reproduzem a desigualdade social e o racismo no país. Trata-se de uma pesquisa qualitativa exploratória-descritiva de cunho bibliográfica.A partir da revisão da literatura, busca delinear as ações cotidianas que concretizam a desigualdade e 0 racismo presente no decorrer dos tempos. Ressalta que o racismo, por envolver aspectos subjetivos em seus matizes conceituais, pode ser identificado na organização da sociedade, uma vez que o racismo estrutural parte desse arcabouço institucional e se materializa em falas e ações. Conclui que os resultados apontamuma diversidade de modos como a desigualdade social e o racismo nela entrelaçado estão presentes na estrutura social, bem como são frutos de um processo que organizou a sociedade desde o período colonial, o que favoreceu a elite ao longo dos tempos.

Palavras-chave: Racismo. Organização social. Desenvolvimento socioeconômico. Políticas Públicas.

\section{RELATIONSHIPS THAT PROMOTE AND REPRODUCE INEQUALITY AND RACISM IN BRAZIL}

\section{Abstract}

The article aims to reflect on relationships that, throughout the history of Brazil, promote, structure and reproduce social inequality and racism in the country. This is an exploratory-descriptive qualitative research of bibliographic nature. From the literature review, we sought to delineate the daily actions that materialize the inequality and racism present throughout time. Racism, as it involves subjective aspects in its conceptual nuances, can be identified in the organization of society, since structural racism starts from this institutional framework and is materialized in speeches and actions. The results show a diversity of ways in which social inequality and racism intertwined in it are present in the social structure, as well as being the result of a process that organized society since the colonial period, which favored the elite over time.

Keywords: Racism. Social organization. Socioeconomic development. Public policies

Artigo recebido em: 03/04/2021 Aprovado em: 26/11/2021 DOI: http://dx.doi.org/10.18764/2178-2865.v25n2p738-757

\footnotetext{
1 Graduação em Direito. Mestre em Desenvolvimento Regional pela Universidade Federal do Amapá (UNIFAP). E-mail: eugeniofurtadoc@gmail.com

2 Graduação em Pedagogia. Doutora em Educação pela Universidade Federal de Fluminense (UFF). Professora da Universidade Federal do Amapá (UNIFAP) no Mestrado em Educação da UNIFAP e no Doutorado em Educação na Amazônia (PGEDA), Associação Plena em Rede-Educanorte. E-mail: eugenia.luz@hotmail.com

${ }^{3}$ Graduação em Pedagogia. Doutor em Teologia pela Faculdades EST. Professor no Mestrado em Educação da UNIFAP e Professor Coorientador no Doutorado em Educação na Amazônia (PGEDA), Associação Plena em Rede-Educanorte. Email: elivaldo.pa@hotmail.com
} 


\section{INTRODUÇÃO}

A história das relações sociais entre os diversos grupos étnicos que compõem a nação brasileira é registrada numa extensa literatura resultante de pesquisas cientificas, de romances e de outros tipos de registros abrangendo o período que vai desde a chegada dos europeus às terras do Novo Mundo até as primeiras duas décadas do século XXI.

Inúmeros registros das violências permearam as interações entre nativos e europeus, que depois incluíram os africanos escravizados e seus descendentes, e que se reproduzem ao longo da história. Para muitos dominados e expropriados essas violências não ficam evidentes por conta da carga ideológica que os leva a aceitar a ideia de fatalidade ou ainda a ideia de que as relações entre esses grupos étnico-raciais configuram, de fato, uma democracia racial.

Diante deste contexto, o presente trabalho apresenta vários registros dessas violências materializadas nas relações interpessoais e institucionais, demonstrando que a desigualdade social imposta, desde 0 início da invasão, e o racismo, ajudaram a estruturar a sociedade brasileira nos diferentes períodos da história nacional consolidando uma ordem sociopolítica que se reproduz em círculo num efeito retroativo, onde se vislumbra o princípio sistêmico-organizacional da retroação numa perspectiva complexa (MORAES; VALENTE, 2008). Assim, de forma disfarçada ou explícita, os negros, os indígenas e os brancos empobrecidos enfrentaram e enfrentam barreiras que os mantêm, até hoje, na posição de subalternos e inferiorizados.

Toda essa percepção da exploração e marginalização desses grupos minoritários possibilita uma reflexão acerca da existência de relações que promoveram, estruturaram e reproduziram a desigualdade e o racismo no Brasil. A presença dessas relações, na atualidade, segue entranhada nas instituições sociais, nos corpos dos indivíduos, inclusive dos explorados, até certo ponto, camuflada por ações de negação da própria sociedade brasileira.

Assim, o objetivo do artigo é refletir sobre relações sociais que promovem, produzem e reproduzem a desigualdade social e o racismo entre os grupos que compõem a nação brasileira, onde brancos de origem europeia, com poder econômico e político, continuam exercendo o domínio e a expropriação dos negros, dos indígenas e dos brancos empobrecidos. 0 resultado do estudo fortalece a tese de que o racismo e a desigualdade social são estruturais no Brasil; o primeiro como estratégia e o segundo como repercussão e critério de distribuição de direitos e privilégios.

A intenção na coleta de registros de ações discriminatórias não foi quantificar, mas pesquisara ocorrência destas ações nos mais diversos espaços de interação social visto que 0 problema foi questionar sobre a desigualdade social e o racismo entranhados na sociedade brasileira 
por meio da normatividade imposta e das interações interpessoais, dentro do tema mais geral do processo de dominação e expropriação que caracterizam a afinidade de propósitos entre os invasores portugueses e a elite econômica brasileira da atualidade. 0 entrelaçamento do racismo e da desigualdade social se explicita com a constatação de que os mais atingidos com as piores condições de vida no Brasil são os negros e os indígenas.

Dentro do campo da bibliografia composta de livros, artigos e teses acadêmicas referentes ao tema da desigualdade social e do racismo na história do Brasil, foram escolhidas aleatoriamente fontes de onde se extraíram registros e informações para a construção do artigo. Na medida em que se encontraram registros que pudessem mostrar relações de promoção, produção e reprodução da desigualdade social e do racismo em determinado espaço temporal e social, passou-se a pesquisar outros espaços-tempos da vida social no Brasil, na mesma ou em outra fonte bibliográfica.

A exploração do tema deu-se concluído com a coleta de registros e informações que demonstraram a presença das relações pesquisadas em variados espaços sociais e tempos históricos de modo a se constatar o caráter estrutural e disseminado na sociedade brasileira. Assim, foram definidos três tempos históricos para orientar a coleta: o colonial, o monárquico e o republicano.

\section{A INVASÃO DA AMÉRICA PARA FINS DE EXPROPRIAÇÃO E A NEGAÇÃO DO OUTRO}

Desde o início da invasão europeia, os povos nativos do Brasil, e depois os africanos que foram trazidos escravizados, experimentaram com os europeus relações de dominação por meio da escravidão e do racismo. As relações de dominação contribuíram para organizar o território ocupado cravando nele as instituições coloniais do Estado metropolitano português. Tal organização evoluiu de forma conservadora mantendo a relação básica de expropriação nos períodos monárquico e republicano que vieram em seguida.

Para efetivar a dominação, os portugueses usaram de forma intensa seu aparelho repressivo massacrando etnias nativas rebeldes e subjugando outras para o trabalho escravo e para auxiliá-los na investida contra outros grupos étnicos ou indivíduos resistentes. Ao mesmo tempo em que reprimiam com armas e outros meios, os portugueses elaboravam e refinavam suas armas ideológicas para que os dominados aceitassem sua situação de expropriados. A investida contra os povos nativos brasileiros, iniciada com a invasão, continuou sendo perpetrada pelas novas elites econômicas que foram assumindo o poder político no Brasil.

Da população de cinco milhões de indígenas habitando o Brasil no ano de 1500, restaram, segundo o censo do Instituto Brasileiro de Geografia e Estatística (IBGE) em 2010, cerca de 890 mil indígenas, com 360 mil vivendo nas zonas urbanas (BRASIL, 2011). Para Gomes (2012, p. 17), foram 
extintos "calcula-se, mais de cinco centenas de povos específicos, de etnias e culturas humanas produto de milhares de anos de evolução e adaptação ao ambiente físico e social em que viviam." Essa realidade que atingiu os povos nativos levou Gomes (2012, p. 16) a escrever,

Independentemente do período histórico - seja colônia, monarquia, república, ditadura ou democracia -, nota-se sempre a má sina dos índios: pressões sobre suas terras, desleixo com sua saúde e sua educação, desrespeito, injustiça e perseguições que sofrem, vindas de todos os quadrantes da nação (inclusive, suspeitamos, do nosso próprio íntimo derrotista). Poderíamos facilmente chegar à conclusão de que não há lugar no Brasil para os índios.

Se durante muito tempo em algumas regiões do Brasil os nativos serviram, e ainda servem, para a estratégia de justificar o domínio territorial da metrópole portuguesa, do império e finalmente da república, nas fronteiras do avanço capitalista os indígenas foram expropriados de suas terras e riquezas e eliminados física e culturalmente enquanto grupos étnicos, para atender o projeto da elite branca e rica associada ao capitalismo internacional.

Fazendo um recorte narrativo pode-se retomar a história a partir do início do século XVI onde se registrou uma guinada histórica que colocou a Europa na condição de protagonista privilegiada de uma forma específica de organização e de produção econômica, denominada modo de produção capitalista, inaugurando novas formas de relação dos humanos entre si e com o meio ambiente que marcam o estágio hegemônico atual da evolução da espécie e da vida no planeta.

As aventuras europeias em águas oceânicas decorreram dos condicionamentos histórico e geográfico dos europeus, com sua incapacidade militar de superar o confinamento imposto pelo império otomano no século XV e a localização do continente na vertente do Atlântico, o que facilitou a chegada ao novo continente e à exploração do potencial econômico das terras do Novo Mundo. A ambição da elite feudal do Estado português em construção foi também fator importante para a expansão do império português.

Quando chegaram ao Novo Mundo, os europeus encontraram grupos humanos habitando o território de onde passaram a extrair riquezas da flora, da fauna, minerais e força de trabalho e no qual implementaram escravidão e genocídios. Concomitantemente, participavam da construção de novas sociedades dando como contribuição suas virtudes e seus vícios, suas vivências, enfim, sua cultura.A atividade colonizadora dos europeus teve como uma das consequências a transferência de riquezas de diversos lugares do planeta para a Europa. Esse acúmulo de riqueza possibilitou alterações políticas naquele continente, levando à formação e consolidação do capitalismo (QUIJANO, 2000).

O novo modo de produção baseado na mais-valia, extraída do trabalho assalariado, não eliminou formas não assalariadas de produção de bens, mas as incorporou ao novo modo de 
expropriação e de acumulação, ou seja, a sociedade capitalista nascente, considerada ideologicamente formação econômica superior, usou intensamente a escravidão indígena e africana na América, não apenas para acumulação primitiva do capital,mas como complementação no processo mais amplo de expropriação.

Segundo Quijano (2000), na concepção eurocêntrica houve uma sequência histórica desde o sistema de trocas, da escravidão, passando pela servidão até a mercantilização da força de trabalho. Assim, nem o colonialismo, nem a escravidão, nem o racismo e tampouco os regimes ditatoriais contemporâneos mostraram-se incompatíveis com o modo de produção capitalista, ainda que o regime de assalariamento tenha se tornado dominante, o que facilitou a ampliação do mercado consumidor e consolidou a nova forma de expropriação por meio da mais-valia.

Formas atávicas e modernas de expropriação coexistem e servem à acumulação nas sociedades capitalistas até hoje. Em pleno século XXI, o trabalho análogo ao de escravidão que ocorre no campo e nos centros urbanos, as grilagens de posses camponesas, as invasões de terras indígenas, as guerras promovidas para acesso a recursos naturais e as ditaduras liberais-capitalistas que reprimem as reivindicações trabalhistas facilitam a expropriação mediante compressão salarial. Essas diversas formas de expropriação coexistem com o capitalismo.

\section{O EUROCENTRISMO COMO JUSTIFICAÇÃO E O RACISMO COMO ESTRATÉGIA DE DOMINAÇÃO E EXPROPRIAÇÃO}

O desenvolvimento da ciência e do conhecimento geral, de forma concomitante com 0 expansionismo colonial europeu, resultou em novos conhecimentos a respeito da natureza humana e da organização do mundo material levando a reformas no modo de perceber e de conceber a vida, o ser humano, a matéria e de reconhecer fenômenos que interagem e constituem a realidade denominada universo. Tais reformas produziram o estágio atual nos diversos campos do conhecimento e possibilitaram a geração de tecnologias utilizadas na medicina, na química, na biologia, na navegação, na comunicação, na produção de alimentos e de outros bens para o uso humano. Essas reformas criaram também concepções sobre a humanidade, levando a novas teorias explicativas da natureza e do comportamento humano.

Sempre imbricadas nas formas de produzir as condições materiais de existência, as teorias sobre a natureza humana nos últimos cinco séculos no ocidente ajustaram e ajustaram-se aos sistemas em processo de entrelaçamento: o econômico emergente (capitalismo), o político (liberalismo) e o religioso (cristianismo), consolidando uma ideologia com lugar privilegiado para os seus costuradores, os europeus. 
Com relação à América foi produzido, a partir da Europa, o racismo, decorrente da ideologia que justificou a superioridade dos dominadores e, em consequência, a organização do trabalho e da cultura com vistas à expropriação, que passou a ser aceita pelos dominados mediante intensa repressão (QUIJANO, 2000). Assim, no processo de dominação europeia construções ideológicas foram constituídas tendo como base a ideia de raça para assegurar o controle sobre os colonizados e a aceitação destes das relações que beneficiaram os europeus.

O processo colonizador europeu nas Américas trouxe para as terras invadidas o modelo hierarquizado de sociedade e a cultura de privilégios e de exploração do trabalho alheio. Assim, nesse modelo estruturaram-se as colônias e se desenvolveram relações de produção e comerciais entre os nativos e os europeus, principalmente espanhóis, portugueses, irlandeses, holandeses, ingleses e franceses.

A nova realidade gerada com a submissão dos povos americanos, africanos e asiáticos decorrente da expansão europeia no planeta, levou à construção da visão etnocêntrica e racista que ideologicamente passou a justificar a imposição dos valores europeus aos dominados com a finalidade principal de expropriação do fruto do trabalho destes e de outros recursos existentes no território invadido. Diziam os europeus serem agentes de uma missão civilizatória e de salvação espiritual dos povos dominados.

As ideias racistas passaram a integrar os diversos aspectos da vida social gerando direitos e privilégios, assim como critérios para sua distribuição, estendendo-se pelas instituições e participando da construção das subjetividades. Uma das elaborações teóricas para fortalecer ideologicamente a superioridade intelectual e moral dos europeus, e assim justificar sua dominação sobre outros povos, foi o reforço da separação entre civilizados e bárbaros ou animalizados, entre os que tinham espírito e os que não o possuíam, sendo apenas corpos. Nessa elaboração o espírito foi colocado em posição hierárquica superior ao corpo e tornado um atributo da identidade europeia (SOUZA, 2017).

$\mathrm{Na}$ esteira desse modo de pensar foi promovida e, ao mesmo tempo, fortaleceu-se a hierarquização dos povos, dos países, das classes sociais e das raças. "As classes superiores são as classes do espírito, do conhecimento valorizado, enquanto as classes trabalhadoras são do corpo, do trabalho braçal e muscular, que as aproxima dos animais" (SOUZA, 2017, p. 21).

No Brasil, essa ideia colocada na prática levou à defesa do assalariamento apenas dos brancos porque os indígenas e os negros, como raças inferiores, tinham obrigação moral de trabalhar para seus senhores sem compensação de ordem financeira. Ao mesmo tempo as tarefas executadas por indígenas e negros tornaram-se aviltantes para a elite branca e opressora. Segundo Samara (1993, 
p. 37) "A necessidade de mão-de-obra e o desprezo pelo trabalho manual estabeleceram vínculos e justificaram a sua presença, de negros escravizados, nas áreas rurais e urbanas." Para reduzir a resistência dos dominados, os europeus produziram e disseminaram o mito de sua superioridade.

A burguesia europeia emergente, insaciável pelo poder, alimentava a guerra fratricida naquele continente, e unia-se no discurso etnocêntrico para justificar seu direito de tutela e de expropriação dos povos de outros continentes. Nesse sentido, o questionamento inicial era se os recém-descobertos pertenciam à humanidade, ou seja, se tinham alma, que era o critério essencial para tal aferição segundo o cristianismo dominante e com forte poder político (LAPLANTINE, 2003).

Com respeito ao Novo Mundo, apesar de opiniões elogiosas sobre o potencial das terras e de seus povos nativos, o que prevaleceu foram as ideias que duvidaram ou negaram um caráter civilizatório ou mesmo a viabilidade civilizatória do Novo Mundo com seus povos originários. Ao mesmo tempo autoridades do conhecimento, como religiosos e filósofos, seguiram dando corpo a teses racistas e preconceituosas de modo geral.

As ideias racistas, apesar de refutadas empíricas e teoricamente no século $\mathrm{XX}$, continuam persistindo nas mentes dogmáticas, conservadoras e obscurantistas, atraindo demagogos e arregimentando ignorantes em pleno século XXI. Os estereótipos construídos para discriminar nativos asiáticos, africanos e americanos persistem ao longo de mais de cinco séculos sendo comum encontrálos nas palavras e atitudes de pessoas de várias partes do planeta. Ainda que algumas situações tenham sido observadas na história de alguns povos, como a falta da escrita, tais circunstâncias não significam uma incapacidade cognitiva. Tampouco caracterizam uma subespécie humana para as teorias científicas atuais.

No século XV, e daí para frente, na linha de construção de um conhecimento sobre 0 território e sobre os povos do Novo Mundo, os europeus conceberam tais nativos como: povos inferiores; selvagens; bárbaros; brutos; preguiçosos; ladrões; sem valores religiosos e morais; sem alma; sujos; etc. Para fortalecer o discurso europeu racista e etnocêntrico foi retomada a ideia cultivada desde os gregos de que a Terra estava dividida em duas partes: de um lado a estupidez, onde vegetavam os seres ali existentes e do outro lado a humanidade onde viviam os europeus. $E$ assim, com uma grande carga de estigmas e de preconceitos foi construída a percepção europeia a respeito dos povos não-europeus, percepção que estruturou ideologicamente a colonização e as relações com os povos dominados. 


\section{RACISMO, IDEOLOGIA E EXPROPRIAÇÃO DE NEGROS E INDÍGENAS NO BRASIL E CONSOLIDAÇÃO DA ESTRUTURA RACISTA}

No Brasil o trabalho intenso de intelectuais conservadores cuidou de estigmatizar os nãobrancos e estereotipar suas culturas, ação que até hoje perdura. Indígenas e negros que fugiam da escravidão foram chamados de vagabundos, assim como o são os trabalhadores atuais que reivindicam maior parcela no resultado do trabalho que realizam. Essa estrutura permanece intacta $\mathrm{e}$ funcionando em todos os espaços da sociedade e produzindo seus efeitos deletérios na vida pessoal e da nação brasileira. Referindo-se diretamente aos negros e à função social do racismo Fernandes escreve (1989, p. 36):

A questão de ser o racismo institucional ou camuflado possui menor importância do que ele representa na reprodução da desigualdade racial, da concentração racial da riqueza, da cultura e do poder, da submissão do negro, como 'raça', à exploração econômica, à exclusão dos melhores empregos e dos melhores salários, das escolas, da competição social com os brancos da mesma classe social etc., e à redução da maioria da massa negra ao 'trabalho sujo' e a condição de vida que confirmam o estereótipo de que 'o negro não serve mesmo para outra coisa.

Os estigmas e estereótipos construídos pelos brancos para marcar e excluir socioeconomicamente indígenas, africanos e os descendentes mestiços foram acompanhados de medidas institucionais e de práticas no seio da sociedade civil para reforço da exclusão. Desde o início da invasão e da colonização tais práticas sociais foram comuns e reiteradas, atingindo inclusive indivíduos europeus que ousavam defender indígenas ou negros.

A força bruta, entretanto, foi a que sempre prevaleceu. Segundo Silva (1990) dentre os direitos do capitão-donatário estava o de escravizar e mandar vender em Portugal, índios capturados na colônia.A implacável guerra de invasão colonial tem registros de deslocamento de indígenas para o interior do território, fugindo das garras dos colonizadores portugueses ou mesmo de genocídioscom aval da sociedade colonial (GOMES, 2012). A história da invasão e da colonização da América também registra a guerra biológica utilizada pelos europeus para assassinar os nativos brasileiros e enfraquecer seu espírito de luta na defesa de seus territórios e de suas próprias vidas.

Na guerra ideológica, o racismo constrói narrativas para tornar a história favorável a determinado grupo. Silva (1990) cita como exemplo desse tipo de ação o filme inglês Zulu, de 1964, dirigido por Cy Endfield, cujo roteiro relata a resistência de militares ingleses ao ataque de guerreiros zulus. 0 ano era 1879, e a Inglaterra travava guerra de invasão colonial contra o reino Zulu. No filme os negros protagonizam os selvagens e assassinos enquanto os brancos ingleses são as vítimas. Assim, foi mantido e reforçado um simbolismo da África e da América como continentes com seres de 
humanidade questionável, bárbaros, incapazes de avanços civilizatórios rumo à europeização, o ápice civilizacional na visão eurocentrista. Almeida (2020) sente o peso da ideologia para o disfarce da desigualdade racial (e social) e para ocultação dos mecanismos que sustentam essa mazela.

No caso do Brasil, mas valendo para todo o processo colonialista europeu, somente escondendo do relato histórico a construção da sociedade colonial com suas atrocidades, espoliação, marginalização e exclusão social é possível torcer a história para contá-la como tarefa de humanização dos invasores e colonizadores. Sem escrúpulos, inclusive de princípios (religiosos, morais), todosos mecanismos e meios possíveis foram usados para consolidar a invasão e manter a dominação.

Freyre (2004) relata o racismo que atingia os mestiços que conseguiram superar barreiras raciais alcançando postos de militares e grau de bacharéis. Esperando ingressar no universo social da elite branca, esses indivíduos sentiram a força do racismo. Dentre vários relatos, três deles são emblemáticos da realidade racista. Em um deles Freyre cita o rebaixamento de um miliciano índio feito pelo marquês de Lavradio pelo fato de o miliciano ter se casado com negra.

A mesma lógica de discriminação e exclusão permaneceu orientando a ação das elites depois de alterado o status de colônia para o de Império. Lê-se no texto constitucional do império brasileiro que os pobres, os escravizados, os libertos e os que não professassem o cristianismo, a religião oficial do Estado imperial, estavam excluídos da gestão deste (BRASIL, 1824). Nota-se ainda que aos escravizados, mesmo depois de libertos, continuava sendo negado o direito à cidadania. $\mathrm{A}$ repressão aos negros e o combate ao abolicionismo também eram realizados por meio dos jornais aliados dos escravocratas.

Prudente (1989), tratando da questão jurídica dos negros na colônia e no império, mostrou o tratamento desigual que sempre manteve os negros em situação de inferiorização, de exclusão e de repressão. Ao comparar as diferenças de tratamento entre negros escravizados e imigrantes a autora expôs que o Direito brasileiro exerceu funções distintas com referência aos dois grupos: Leis Imigratórias e Leis Escravistas. Na medida em que ganhou importância econômica o trabalho dos africanos escravizados, e depois dos imigrantes, a história oficial criou um vazio quanto à participação dos indígenas, apesar das ações públicas e privadas ficarem fortemente ligadas ao avanço sobre seus territórios.

Contudo, os genocídios e a escravização, apesar de proibidos, continuaram a ser perpetrados por fazendeiros e latifundiários. Em pleno século XX ouve-se nas regiões norte e nordeste relatos de que indígenas, principalmente do sexo feminino, foram sequestradas de suas aldeias para serem serviçais nas zonas urbanas. $E$ os assassinatos de indígenas por questões ligadas à terra continuam a fazer parte do noticiário nacional.

A mudança de status político do Brasil, com inauguração da república em 1889, não se 
refletiu em promoção para a inclusão dos negros e dos indígenas. Referindo-se à situação dos negros, Dantas (2012, p. 88) escreveu: "o que a população negra viu nas primeiras décadas republicanas foi a consolidação de projetos sócio-políticos excludentes e a ideia de raça se fortalecer como critério de classificação social e justificativa para a desigualdade". Assim, o racismo secularmente introjetado na sociedade brasileira manteve-se incólume reproduzindo a desigualdade social e a violência étnicoracial.

Os negros brasileiros muitas vezes não podiam frequentar bares, hotéis, clubes e salões de baile. Também enfrentaram restrições no acesso a instituições educacionais públicas e privadas, entraves para assumir cargos públicos ou vagas conquistadas em concursos públicos, além de intimidação e violência policial, estando expostos a formas de tratamento racialmente desiguais, como se a escravidão ainda existisse (DANTAS, 2012, p. 88).

Em 1894, início da República, pais reclamaram da discriminação na escola que atingia seus filhos não brancos (VEIGA, 2016, p. 294) "[...] seus filhos são destratados pela professora que prodigaliza o desprezo aos que não vestem a pelle branca e que não dissimula o desprazer que experimenta em tratar com meninos de cor e de cabello ruim! [...]". Outro relato, sem data, registrado por Veiga (2016) expressa o racismo na manifestação de um inspetor de escolas. O agente público racista demonstra desprezo pelos negros que não conseguiram superar as barreiras sociais impostas, e expressa ódio pelos que ousaram desafiar a normalidade social:

A professora é uma preta boçal, sirpinamente (sic) ignorante, quase sem inteligência [...]. Para o cumulo desta desgraçada instrução primária a mestra é normalista titulada pela Escola Normal de Ouro Preto. Nunca encontrei uma professora tão sem inteligência! Admiro pasmo como é que esta preta conseguiu titular-se pela Escola Normal da Capital [...] (VEIGA, 2016, p. 295).

Em outro excerto recolhido por Veiga (2016) tem-se o relato de um ex-estudante de escola pública em Minas Gerais sobre suas memórias no ano de 1910. O relato foi publicado na Revista do Ensino, ano IX, n. 198, jan-mar. 1951, p. 23:

Outro fato que me intrigava naquela época era a desigualdade social. Filhos de pais que exerciam profissões "mais nobres" não gostavam de relações com os colegas filhos de operários e de lavradores, muito embora existisse certa "aristocracia" rural. O preconceito, então, contra os pretinhos era muito grande. Ninguém gostava de ficar perto dos poucos que frequentavam a escola (VEIGA, 2016, p. 272-273).

Em sua ação deletéria o racismo cria obstáculos para o acesso de suas vítimas aos bens sociais, entrelaçando-se a outras estratégias de discriminação social e de expropriação econômica que atingem pretos, pardos, indígenas, e alguns brancos empobrecidos. Para tal discriminação e exclusão as instituições da elite conservadora e o Estado, sob seu controle, agem de forma concatenada, violentando individual e coletivamente os dominados.

Dantas (2012) também identificou o preconceito e o racismo na área da saúde pública 
onde, segundo a autora, as autoridades do início da república priorizavam o combate a doenças que atingiam os imigrantes em detrimento daquelas que atingiam fortemente os negros, como a tuberculose. Além disso, os lugares onde morava a parte mais pobre da população eram olhados como antros de promiscuidade, cheios de vícios e perigosos para a saúde pública.

Fazendo uma leitura das disputas no campo da elite branca com seus projetos que resultaram na república, Fernandes (1989, p. 14) concluiu que nem o branco 'rebelde' nem a República "enfrentaram a descolonização, com a carga que ela se impunha, em termos das estruturas raciais da sociedade. Como os privilégios construídos no período escravista, estas ficam intocáveis e intocadas."

No âmbito do Estado brasileiro decisões fundadas em critérios estritamente subjetivos, discriminatórios, racistas foram tomadas para excluir grupos sociais, como no fato citado em Rodrigues (2008) que verificou a prática discriminatória e racista na formação do oficialato do exército brasileiro nas décadas de 1930 e 1940, negando acesso a negros e a outros grupos ideologicamente discriminados. Assim, os negros foram impedidos de tornarem-se oficiais do Exército não porque não fossem capazes físico-intelectualmente de exercer as atribuições do cargo, mas porque eram negros. É pertinente destacar que essa prática se estendeu mesmo após o fim do Estado Novo. Em todos os espaços da vida social brasileira o racismo e a repressão se fizeram presentes como característicos das relações entre as elites econômicas brancas e os não brancos ou brancos empobrecidos.

No início da década de 1960, a mobilização dos trabalhadores reivindicando das elites ricas uma reforma agrária que desconcentrasse as terras e lhes desse 0 direito legal de cultivá-las, gerou incisiva reação dos setores da igreja católica aliados dos latifundiários (MORAES, 1989). Em defesa dos latifundiários os setores conservadores da igreja católica reagiram posicionando-se inclusive contra a orientação da Conferência Nacional dos Bispos do Brasil (CNBB).

Guimarães (2004) escreveu que no final de 1989, um comerciário, que se identificou primeiro como branco e mais tarde como pardo, foi preso em flagrante delito por ter ofendido uma mulher chamando-a de urubu, macaca e negra. 0 autor também constatou que alguns crimes de racismo acabam tipificados como outras condutas criminosas previstas na Lei federal n. 7716, de 1989 ou em outras leis penais. Em seu trabalho Guimarães (2004, p. 89) se utiliza de " 547 matérias publicadas entre 1989 e 1994 sobre queixas de discriminação racial, registradas por 44 jornais diários e 2 revistas semanais, editados em 20 cidades brasileiras de 14 estados da federação." A partir desse material, Guimarães identifica o racismo, a restrição de direitos e a discriminação racial corrente no Brasil no período pesquisado. Esses fatos, juntamente com outros que atingem pretos, indígenas, pardos, pobres e mulheres, continuam aparecendo com frequência nos noticiários nestas duas primeiras décadas do século XXI.

Hasenbalg (1979) fez um levantamento de 48 registros de discriminação racial e racismo 
noticiados pela imprensa no período de 12 de setembro de 1968 e 06 de setembro de 1977, dentre os quais 13 foram selecionados, mostrando a variedade de formas, meios e lugares onde o racismo se expõe. A simples condição da cor negra foi - e ainda hoje é - motivo para a segregação social. Hasenbalg (1979) percebe uma ação sistemática massacrando os negros de todas as formas possíveis, vindas de diversos espaços sociais e de diversos agentes públicos e da sociedade civil, inclusive de sujeitos negros. No caso dos negros, Paula (2003, p. 194) afirma que "a auto-rejeição (sic) não indica racismo dos negros, mas revela que os negros, não suportando o sofrimento que o racismo Ihes impõe, tentam encontrar meios que possibilitem neutralizar sua negritude".

Para esses grupos marginalizados de indígenas e negros, a cor, a miscigenação, a cultura e o modo de vida, inclusive sua solidariedade, são referidos ideologicamente pelas elites opressoras e seus agentes como atraso civilizatório e motivos de sua situação de pobreza, de sua incompetência intelectual e de sua suposta propensão à desonestidade e à corrupção. De tanto serem estigmatizados com atributos depreciativos os oprimidos acabam reproduzindo a violência introjetada.

Alguns oprimidos, na situação de alienados, são incapazes de perceber a estrutura e a ordem opressoras. Assim, tentam, por dentro dessa estrutura, encontrar saída para se livrarem dos estigmas impostos pela elite em função da sua cor não branca ou da sua situação social de pobre. Então fazem de tudo para se parecerem com os padrões das classes dominantes.

\section{RACISMO, DESIGUALDADE SOCIAL E POLÍTICAS PÚBLICAS}

Enquanto disseminam o discurso de combate à corrupção (que elas mesmas perpetram), e ao racismo, as elites continuam a promover a concentração da riqueza e a desigualdade socioeconômica. O fenômeno recente da "Lava Jato" é um exemplo do uso do aparelho de Estado no processo de expropriação (SOUZA, 2017). Foi nesse contexto, sob a égide do capitalismo e do ideário liberal que entrelaça racismo, corrupção e expropriação, que a nação brasileira foi (e continua) sendo construída, reproduzindo de forma cada vez mais agravada a exclusão econômica e social dos cidadãos de fora do grupo proprietário, alijando-os sistematicamente do usufruto legítimo da riqueza social.

De modo geral, os excluídos são também submetidos a uma ideologia que sustenta tal realidade excludente por meio do estímulo à competição, que está presente em todos os espaços da vida moderna, a começar pela família e pela escola. Pois, "é necessário, para quem domina e quer continuar dominando, se apropriar da produção de ideias para interpretar e justificar tudo o que acontece no mundo de acordo com seus interesses" (SOUZA, 2017, p. 25). 
Para Souza (2017), as instituições exercem forte influência na construção dos sujeitos, iniciando na família, com os olhares de aprovação e reprovação sobre a criança, indicando os comportamentos desejáveis ou não. A imposição de horários, por exemplo, também faz parte do processo de socialização, visando a disciplina. Outra instituição, a escola, aprofunda a socialização iniciada na família, construindo socioculturalmente o cidadão inserido e engajado na reprodução do modo de vida hegemônico.

No final do século XIX, com o início da formação de uma classe trabalhadora urbana ligada à nascente industrialização no Brasil, e com a chegada de imigrantes europeus, alguns com experiência de lutas operárias na Europa, o Brasil experimentou mais intensamente as jornadas reivindicatórias dos trabalhadores por melhores salários, jornada diária de oito horas; salubridade nos locais de produção, segurança previdenciária e combate à exploração de crianças, dentre outras reivindicações.

As elites econômicas reagiram a essas mobilizações com repressão privada e estatal mediante demissões, perseguições e assassinatos. Uma legislação repressiva e controladora foi produzida pelo Estado. O poder judiciário também, sob controle das elites, agiu (e ainda age) com todo o rigor possível para reprimir e impedir as lutas e as vitórias dos trabalhadores que buscavam o direito ao usufruto da riqueza gerada com o próprio trabalho. Numa sociedade estruturada para gerar expropriação e desigualdade social, o sistema repressivo implementado pela polícia e pelo judiciário é pilar de sustentação do regime.

Igual repressão e expropriação por parte das elites brasileiras sofreram os trabalhadores do campo e as nações indígenas, envolvendo expulsões, assassinatos e genocídios por parte dos latifundiários. Portanto, a história do Brasil sob a ótica dos trabalhadores é a história da expropriação e da exclusão destes dos ganhos sociais, gerando, por outro lado, uma elite corrupta, violenta, concentradora da riqueza nacional e inescrupulosa.

O senhor, o patrão, enquanto expropria e enriquece, continua chamando 0 trabalhador, que é o produtor de fato da riqueza, de vagabundo, incapaz, para que este não perceba o real motivo de sua exploração e de sua pobreza. 0 explorador faz o explorado aceitar essa condição atribuindo-a à sua incompetência natural ou até mesmo a um deus que opera a prosperidade apenas para alguns escolhidos.

Os estudos realizados pelo IBGE mostram que durante o século XX o Produto Interno Bruto (PIB) cresceu 100 (cem) vezes. Tais estudos revelam também que o crescimento não repercutiu positivamente no conjunto da sociedade (IBGE, 2006). No início do século XXI o que se constatou foi um significativo contingente de pessoas desempregadas ou subempregadas, numa economia, tanto no meio urbano como no meio rural, com grau crescente de tecnologia da automação, o que acentuou o 
declínio na criação de empregos, apesar dos ganhos de produtividade.

No período estudado pelo IBGE, referente ao século $\mathrm{XX}$, houve intenso processo de urbanização, mas o contingente que foi expulso do campo não foi absorvido pelos empregos urbanos gerados. Por outro lado, as terras tornaram-se mais concentradas, aumentando o número de latifúndios (IBGE, 2006). O desenvolvimento brasileiro ao longo de cinco séculos de história somente serviu para o bem-estar de uma minoria.

E essa realidade excludente continua sendo reforçada pela ideologia de que os proprietários privados precisam ganhar mais para manter os investimentos necessários ao crescimento econômico do país. Nesse sentido, legitima-se o Estado estruturado para que a renda nacional continue fluindo para a posse e controle de um pequeno grupo cujo objetivo é apenas obter e aumentar lucros e não desenvolver a nação econômica e socialmente. 0 altruísmo da elite rica e branca vai até 0 limite do não comprometimento de seus lucros maximizados e outros ganhos patrimoniais. Ou seja, da parte da elite até a solidariedade é condicionada à ampliação de seus negócios e do lucro.

Com discurso da necessidade de poupança e de aporte de vultosos recursos para implantar projetos de infraestrutura e de promoção do desenvolvimento econômico (BARQUERO, 2001), a elite brasileira justifica ideologicamente a concentração e o crescimento do bolo em suas mãos, tirando esse papel desenvolvimentista do Estado, uma instituição mais permeável à pressão da sociedade ainda que, de fato, esteja controlado pelas elites econômicas.

No liberalismo brasileiro o Estado arrecada e transfere para os ricos vultosos recursos financeiros e patrimoniais por meio dos tributos, onde os mais pobres são os que, proporcionalmente, mais contribuem para alavancar empresas e bancos privados tornando também privada a riqueza que moralmente pertence à nação inteira, se for tomado como princípio distributivo o trabalho produtivo e 0 sujeito que o realiza. A concentração da riqueza aumenta o poder econômico das elites dominantes e reforça a submissão da sociedade aos seus interesses de classe.

Para perceber todo esse processo de expropriação é importante compreender o papel do Estado como legitimador e repressor a serviço da classe dominante. O Estado é uma instituição histórica gerada no processo de consolidação da desigualdade econômica entre os grupos de determinada sociedade (ENGELS, 1995) e sua função foi assegurar por meio da repressão uma ordem que favorecia e garantia privilégios ao grupo que detinha seu controle. Para o liberalismo, o Estado foi criado para servir ao indivíduo e, assim, concebem o Estado como uma instituição neutra. Na prática, o que se percebe, de modo geral, são as instituições estatais privilegiando interesses políticos das elites econômicas, inclusive facilitando-lhes o acesso aos recursos públicos.

Assim, dependendo da forma como são escolhidos os agentes que ocupam as funções 
estatais de decisão, pode-se ter um Estado altamente favorável aos interesses dos grandes proprietários privados, como no caso do Brasil e nos demais países liberais. De qualquer maneira, na periferia do capitalismo a prevalência dos interesses privados como definidor das políticas estatais é evidente. Os detentores do poder econômico, que são também detentores do poder político, mantêm o Estado a seu serviço para viabilizar seus propósitos, tanto do ponto de vista individual como também coletivo, de grupo. E as políticas públicas, na prática, são privadas e em detrimento da sociedade como um todo (SANTOS, 2008).

Para justificar essa política de privilégios e expropriação, a elite faz o discurso do Estado (que ela mesma controla) corrupto e ineficiente, fatos esses reais, mas promovidos pelas próprias elites diretamente ou por meio de seus eleitos e indicados, que gerem as instituições, manipulam os recursos públicos, fiscalizam as próprias empresas, fazem as licitações, controlam os preços administrados, distribuem subsídios, financiam investimentos privados com custos aquém do mercado, perdoam dívidas de grandes sonegadores, sabotando políticas distributivas do Estado e transferindo os recursos públicos para bolsos dos mais ricos. A organização estatal a serviço das elites econômicas ricas reforça e legitima sua ação de dominação e de expropriação sobre os demais grupos sociais.

Para complementar a estratégia de enriquecimento das elites brasileiras, há o discurso da mesa farta com o argumento de que caso aumentem os ganhos dos ricos, aumentarão também as rendas para os trabalhadores. 0 crescimento econômico ocorrido no Brasil durante cinco séculos, especialmente durante o século XX, mostra que a distância entre os mais ricos e os mais pobres, estes os produtores diretos da riqueza nacional, foi mantida com prejuízo dos trabalhadores (SANTOS, 2008).

No lado oposto ao das elites com alto padrão de consumo encontra-se o grande contingente de trabalhadores e trabalhadoras excluídas do básico para exercer a cidadania. Tal contingente, originalmente escravizado, foi expulso do campo, mas continuou sendo expropriado pelo sistema produtivo, passando a formar o contingente de trabalhadores com salários aviltados, com empregos e condições indignas de trabalho, desempregados, subempregados, vivendo de bico, sendo empurrados pela força do poder econômico das áreas urbanizadas para as áreas insalubres das periferias urbanas e das favelas.

$\mathrm{Na}$ obra organizada por Arretche (2015) foram tratadas cinco dimensões consideradas importantes para discorrer sobre a desigualdade social: a participação política, a relação entre educação e renda, as políticas públicas de caráter universalizante, a demografia e a dinâmica na composição do mercado de trabalho. $O$ entrelaçamento dessas dimensões comporia um retrato mais amplo e detalhado da realidade.

A verificação dessas dimensões, considerando a realidade brasileira no período de 1960 a 
2010, levou à conclusão geral de que no período ocorreram significativos avanços na sociedade brasileira como, por exemplo, o direito ao voto das pessoas não alfabetizadas (LIMONGI; CHEIBUB; FIGUEIREDO, 2015) e a participação cada vez mais intensa das mulheres nos diversos espaços sociais, a começar pela educação (OLIVEIRA; VIEIRA; MARCONDES, 2015).

Tais mudanças, contudo, revelaram uma estrutura geradora e perpetuadora da desigualdade social histórica, que discrimina e exclui mulheres, negros e indígenas. Além disso, tal estrutura manteve a distância entre os mais ricos e os mais pobres, em que conte uma trajetória de redução dessa distância a partir de meados da década de 1990 e na primeira década do século XXI (ARRETCHE, 2015). A origem social e racial das pessoas continuou afetando o acesso à escola e 0 desempenho escolar, ou seja, é a desigualdade social afetando as oportunidades educacionais que num movimento de retroação mantém a desigualdade social.

Com a universalização do acesso ao ensino fundamental na década de 2010, as dificuldades então verificadas nesse nível de ensino (origem rural, a escolaridade dos pais, a renda familiar, sexo e cor/etnia), ainda que não tenham sido completamente eliminadas, foram deslocadas para o ensino médio e superior, gerando taxas de conclusão muito inferiores às de entrada (ARRETCHE, 2015). Além disso, constatou-se a superposição de desvantagens com relação aos não brancos, prejudicando-os ainda mais. Adicionalmente, ainda em 2010 havia no ensino superior uma superposição de desvantagens por cor e renda, pois os negros pobres encontravam mais dificuldades para atingir níveis superiores de escolaridade do que os brancos pobres (ARRETCHE, 2015).

As desvantagens dos não-brancos brasileiros também estão ligadas às regiões e locais de moradia, pois estes são levados a concentrar-se nos espaços menos atendidos com políticas públicas, como o meio rural e periferias urbanas, assim como nas regiões norte e nordeste. Nesses espaços se entrelaçam baixa renda, trabalho precário, carência de escolas, de postos de saúde e de infraestrutura, como transporte, energia elétrica, água e saneamento. E quando tais serviços são oferecidos, o seu funcionamento é precário quanto à qualidade e à continuidade.

A respeito das raças e do gênero, Arretche (2015) declara que tanto a presença quanto a resiliência do racismo e do patriarcalismo na sociedade brasileira na primeira década do século XXI permanecem bastante estáveis, pois os pretos têm menos chances de ingressar no ensino superior e, quando conseguem, o fazem nas carreiras de menor prestígio. Quanto às mulheres, pretas e pardas recebem rendimentos inferiores, mesmo quando possuem o mesmo diploma que os homens brancos.

Apesar dos avanços legislativos há, segundo Arretche (2015), a constatação de que as políticas parecem ter um efeito limitado sobre as desigualdades persistentes de cor e de gênero, o que se verifica de fato na menor repercussão da lei vigente no cotidiano dos negros, principalmente quando 
o conteúdo de tal lei trata de direitos. E isso ocorre em razão da omissão dos órgãos públicos encarregados da aplicação da norma legal.

\section{CONSIDERAÇÕES FINAIS}

A desigualdade social e o racismo são fenômenos que atingem ao mesmo tempo, e de forma negativa, os negros e os indígenas que são os grupos raciais mais expropriados economicamente no Brasil. Tais fenômenos são reproduzidos por meio de relações específicas as quais têm o escopo de excluir indivíduos e grupos do usufruto das riquezas sociais. Tais relações foram inicialmente planejadas e implementadas intencionalmente por uma elite econômica europeia branca, majoritariamente portuguesa, que organizou a colônia e a escravidão de nativos e de africanos.

Na medida em que o status político do Brasil foi sendo alterado, passando para monarquia e depois para república, as alterações políticas preservaram as elites econômicas remanescentes do período anterior na condição de elites dominantes, mantendo a mesma ordem expropriadora, racista e causadora da desigualdade social. O Estado, legitimado para a violência, agiu para a manutenção do status quo. As mudanças feitas nele, pelas próprias oligarquias, apenas o ajustam para manter a ordem opressora e os privilégios dessas velhas-novas oligarquias.

Com relação aos imigrantes houve políticas de integração à sociedade brasileira ainda que o objetivo principal das elites econômicas fosse abastecer-se de mão de obra. Com relação aos indígenas, a intenção era uma liberdade tutelada e o controle de seus territórios. No caso dos negros o objetivo era exclusivamente obter força de trabalho desse grupo humano, sendo-lhes intensamente negada a integração social como cidadãos no mesmo patamar dos brancos ou mesmo dos indígenas. Toda a política direcionada aos negros, principalmente nos períodos imperial e republicano, foi para apagar sua participação na construção da sociedade brasileira. A política de embranquecimento foi um exemplo dessa trágica e cruel política racista.

Para manter e alavancar seus interesses de expropriação, os invasores, escravocratas, latifundiários, capitalistas utilizaram todos os meios possíveis, legais e ilegais, para submeter, dominar e expropriar outros seres humanos. Além da violência explícita contra os corpos, utilizaram-se da violência simbólica e de ideologias para sedimentar suas narrativas, justificando a opressão, a dominação e a expropriação. 0 projeto do opressor introjetado no oprimido, o aliena e promove nestas atitudes de defesa da ordem que o oprime.

As mudanças sociais no Brasil, com seu caráter conservador, indicam que estas foram realizadas sob controle das elites econômicas e que a força dos oprimidos não foi suficiente para dar a estes a autoria e a direção do processo de mudança. A estrutura ideológica construída pela elite branca 
e rica cumpre sua função de impedir que os dominados superem seus condicionamentos e construam ou legitimem outras ideologias alternativas mais consentâneas com seus interesses de libertação.

O tensionamento atual indica, contudo, que houve avanços reais e formais (na esfera legal) em alguns aspectos, gerando uma reação da elite branca, racista e conservadora. Em outros aspectos o racismo refinou-se, como no caso da política de meritocracia implementada pelo neoliberalismo. $O$ estudo desse refinamento dos meios e instrumentos de dominação como o discurso da meritocracia e a universalização do acesso às redes sociais contribui para identificar as tensões atuais no embate que entrelaça racismo, desigualdade social e expropriação no Brasil.

\section{REFERÊNCIAS}

ALMEIDA, Silvio Luiz de. Racismo estrutural. São Paulo: Jandaíra, 2020.

ARRETCHE, Marta. (org.). Trajetórias das desigualdades: como o Brasil mudou nos últimos cinquenta anos. São Paulo: Unesp, 2015.

BARQUERO, Antonio V. Desenvolvimento endógeno em tempos de globalização. Trad. Ricardo Brinco. Porto Alegre: Fundação de Economia e Estatística, 2001.

BRASIL, Constituição Política do Império do Brasil, elaborada por um Conselho de Estado e outorgada pelo Imperador D. Pedro I, em 25.03.1824. Disponível em:

http://www.planalto.gov.br/ccivil_03/constituicao/ constituica024.htm. Acesso em: 12 jan. 2021.

BRASIL, Lei n. 7716 de 05 de janeiro de 1989. Define os crimes resultantes de preconceito de raça ou de cor. Diário Oficial da União - Seção 1 - 06/01/1989, página 1.

BRASIL. Instituto Brasileiro de Geografia e Estatística - IBGE. Censo Demográfico 2010. Rio de Janeiro: IBGE, 2011.

BRASIL. Instituto Brasileiro de Geografia e Estatística - IBGE. Estatísticas do século XX. Rio de Janeiro: IBGE, 2006.

DANTAS, Carolina Vianna. Mobilização negra nas primeiras décadas republicanas. In: DANTAS, Carolina Vianna; MATTOS, Hebe; ABREU, Martha (orgs.). 0 negro no Brasil: trajetórias e lutas em dez aulas de história. Rio de Janeiro: Objetiva, 2012, p. 85-98.

ENGELS, Friedrich. A origem da família, da propriedade privada e do Estado. Trad. Leandro Konder. 13. ed. Rio de Janeiro: Bertrand Brasil, 1995.

FERNANDES, Florestan. Significado do protesto negro. São Paulo: Cortez, 1989.

FREYRE, Gilberto. Sobrados e mucambos: decadência do patriarcado e desenvolvimento do urbano. 15. ed. rev., São Paulo: Global, 2004.

GOMES, Mércio Pereira. Os índios e o Brasil: passado, presente e futuro. São Paulo: Contexto, 2012. 
GUIMARÃES, Antonio Sergio Alfredo. Preconceito e discriminação: queixas de ofensas e tratamento desigual dos negros no Brasil. 2. ed. São Paulo: FUSP, 2004.

HASENBALG, Carlos Alfredo. Discriminação e desigualdades raciais no Brasil. Trad. de Patrick Burglin. Rio de Janeiro: Graal, 1979.

LAPLANTINE, François. Aprender antropologia. Trad. Marie-Agnés Chauvel, São Paulo: Brasiliense, 2003.

LIMONGI, Fernando; CHEIBUB, José A.; FIGUEIREDO, Angelina C. Participação política no Brasil. In: ARRETCHE, Marta. (org.). Trajetórias das desigualdades: como o Brasil mudou nos últimos cinquenta anos. São Paulo: Unesp, 2015, p. 23-49.

MORAES, Dênis de. A esquerda e o golpe de 64: vinte e cinco anos depois, as forças populares repensam seus mitos, sonhos e ilusões. 2. ed. Rio de Janeiro: Espaço e Tempo, 1989.

MORAES, Maria Cândida; VALENTE, José Armando. Como pesquisar em educação a partir da complexidade e da transdisciplinaridade? São Paulo: Paulus, 2008.

OLIVEIRA, Maria Coleta; VIEIRA, Joice Melo; MARCONDES, Glaucia dos Santos. Cinquenta anos de relações de gênero e geração no Brasil: mudanças e permanências. In: ARRETCHE, Marta. (org.).

Trajetórias das desigualdades: como o Brasil mudou nos últimos cinquenta anos. São Paulo: Unesp, 2015, p. 309-333.

PAULA, Rogéria Costa de. Construindo consciência das masculinidades negras em contexto de letramento escolar: uma pesquisa-ação. In: LOPES, Luis Paulo da Moita (org.). Discursos de identidade: discurso como espaço de construção de gênero, sexualidade, raça, idade e profissão na escola e na família. Campinas, SP: Mercado de Letras, 2003, p. 181-208.

PRUDENTE, Eunice Aparecida de Jesus. O negro na ordem jurídica brasileira. Revista da Faculdade de Direito da USP, v. 83, jan. 1988, São Paulo: USP, 1989, p. 135-149. Disponível em: http://www.revistas.usp.br/rfdusp/issue/view/5417. Acesso em: 20 mar. 2019.

QUIJANO, Anibal. Colonialidad del poder, eurocentrismo y América Latina. In: La colonialidad del saber: eurocentrismo y ciência sociales - perspectivas latinoamericanas. Buenos Aires: CLACSO, 2000, p. 201-246. Disponível em: http://bibliotecavirtual.clacso.org.ar/ar/ libros/lander/quijano.rtf. Acesso em: 4 jan. 2019.

RODRIGUES, Fernando da Silva. Discriminação e intolerância: os indesejáveis na seleção dos oficiais do Exército Brasileiro (1937-1946). Antíteses, Ahead of Print do v. 1, n. 2, jul./dez. de 2008, p. 455474. Disponível em: www.uel.br/revistas/uel/index.php/antitesesAcesso em: 24 abr. 2019.

SAMARA, Eni de Mesquita. A família brasileira. 4. ed. São Paulo: Brasiliense, 1993 (Coleção Tudo é História).

SANTOS, Milton. 0 espaço dividido: os dois circuitos da economia urbana dos países subdesenvolvidos. Trad. Myrna T. Rego Viana, 2. ed. 1. reimp. São Paulo: USP, 2008.

SILVA, Francisco Carlos Teixeira da. Conquista e colonização da América Portuguesa. In: LINHARES, 
Maria Yedda (org.). História Geral do Brasil. 9. ed. Rio de Janeiro: Elsevier, 1990, p. 33-93.

SOUZA, Jessé. A elite do atraso: da escravidão a lava jato. Rio de Janeiro: Leya, 2017.

VEIGA, Cyntia Greive. "Promiscuidade de cores e classes": tensões decorrentes da presença de crianças negras na história da escola pública brasileira. In: FONSECA, Marcus Vinícius; BARROS, Surya Aaronovich Pombo de (orgs.). A História da educação dos negros no Brasil, Niterói: EdUFF, 2016, p. 271-302. 